\title{
CNC Lathe Programming and Machining of Thin-walled Parts Macro Program
}

\author{
Zhu Xiurong and Zhang Guangcheng \\ College of Mechanical Engineering, Jilin Teacher's Institute of Engineering and Technology, \\ Changchun, Jilin, china 130052 \\ E-mail: zxr67811@163.com
}

\begin{abstract}
In this paper, thin-walled parts macro programming design and examples of realization, find its CNC lathe, the shape of the processing rules, compiled macro program implementation. Compared with the ordinary procedure by macro program, analysis of the necessity of its existence. Macro program has proved irreplaceable role in $\mathrm{CNC}$ machining, so engaged in $\mathrm{CNC}$ machining staff recognize the importance of the macro process.
\end{abstract}

Keywords-CNC Machining ; Thin-walled Parts ; Macro; Programming and Processing

\section{INTRODUCTION}

I have been engaged in $\mathrm{CNC}$ professional practice teaching and theoretical teaching, guiding students to participate in the national competition numerical skills competition, but also deep into the enterprise jobs CNC machining work. In the teaching process, students claim $\mathrm{NC}$ obtain professional skills certificate, in which students apply advanced numerical control requirements must master the macro programming skills, vocational school skills competition is more of a macro program put forward higher requirements. In business, there are few programmers will use the macro programming. Most companies use computer automatic programming, few companies use manual G-code programming, the role of the macro program that cannot be reflected, many employees macro program by learning, improve their own level CNC programming to solve the previously programmed by computer automatically and manually $G$ code programming can not solve the processing problems, greatly improving production efficiency and product quality. In the mold processing enterprises, many mold shape parts of similar size is inconsistent, macro here there is a very wide range of applications of space, can be consistent with the shape of a part programmed with a macro program, just modify the relevant parameters to the actual application size. Circle Mold Co., Ltd. Hebei Science and Technology Plan undertaken subject "car cover mold CNC machining mode and process optimization." The project is the study of the fine mold surface machining principle, the use of hierarchical contour programming methods to achieve a small amount of cutting, fast feed efficient processing, improved macro parameter library. After the implementation of the project to improve the mold quality, high efficiency, energy saving effect is obvious, the economic and social benefits significantly [2]. In the usual process of teaching, I deeply felt the need to learn a macro program, so this macro program macro programming research at $\mathrm{CNC}$ lathe thin-walled parts. Through this study, so in $\mathrm{CNC}$ machining staff recognize the importance of the macro process of necessity and should be familiar with the use of a macro program. ${ }^{1]}$

\section{THE MACRO DEFINITIONS AND CHARACTERISTICS}

NC during manual programming, Certain values with variable assignment method to express, Read the numerical CNC system is variable and variable values are assigned a regular change, When programming may be added math and logic operations, prepared by hand out of the program in this way is called a macro.

CNC programming using macro advantages:

Using variables compiled NC program, it will make a regular shape of the parts programming easier. Program when writing more readable, easy to modify the program to read the program. When reading program $\mathrm{CNC}$ machine tools also liked to read such a program, because the macro will read faster CNC machine tools, processing machines faster response speed.

CNC machined parts in some shapes using computer programming software development process cannot be achieved, such as an elliptical shape thread, variable pitch thread, in the sphere processing thread, these complex shapes only use a macro program is the best solution.

The use of macros compiled programs usually are less than 70 lines, it would CNC machine storage capacity greatly enhanced. Can improve the machining efficiency, but also improve the ability of the preparation of programming staff.

\section{ORDINARY MANUAL PROGRAMMING AND MACRO}

\section{PROGRAMMING CONTRAST}

The role of ordinary manual programming instruction processing code is fixed, entirely developed by $\mathrm{NC}$ programming system manufacturer, during programming, the programmer can use the programming instructions specified machining programs. Since the general instruction in the use of hand-woven single usage, unable to adapt to the programming of complex parts, a lot of numerical control system manufacturers based on the common programming instructions on the increase in macro programming function.

Manual programming can only be used when ordinary numerical programming, because it is a fixed value, it cannot be mathematical programming, $\mathrm{CNC}$ machine tools when reading the program does not jump to another block, can only be read line by line from top to bottom, 
use when the macro compiled NC program, using variable assignment methods, can perform mathematical operations and logic operations between macro variables, when reading program $\mathrm{CNC}$ machine tools are available upon request to jump to the desired block, the program flexible.

TABLE I MACRO PROGRAMMING BRIEF COMPARISON WITH ORDINARY MANUAL PROGRAMMING

\begin{tabular}{ll} 
Ordinary manual programming & Macro Programming \\
\hline Use only constants & Use variables and assign values to variables \\
Not operations between constants & Operations between variables can \\
Program can only order, can not jump & Program run can jump \\
Ordinary manual programming & Macro Programming \\
\hline
\end{tabular}

\section{CNC LATHE PROGRAMMING AND MACHINING OF} THIN-WALLED PARTS MACRO PROGRAM

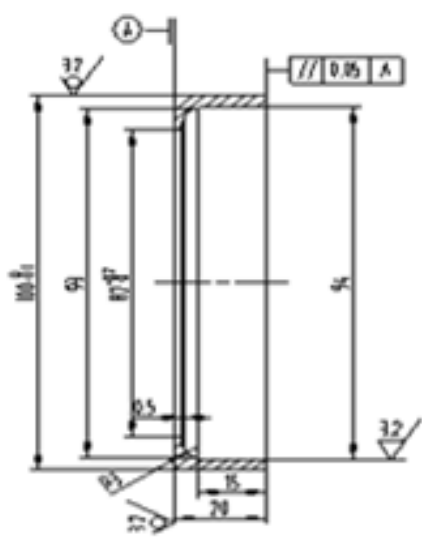

Figure 1. Thin-walled Parts Drawing

\section{A. Analyze Parts Diagram, Determine the Installation \\ Reference}

Parts shown in Fig, and an end face of the cylindrical part machining has not displayed according to the technical requirements of the drawings illustrate the two faces of the parts does not require precision machining of relatively high. Taking into account the structure and shape of parts, as well as the actual process used by the machining characteristics, select the part of the plane for the positioning surface clamping fixture using standard anti-lathe clamping jaws. [2]

\section{B. Select the Processing Method}

Parts of the inner contour of roughness $\mathrm{Ra}=3.2$, so when turning, you can call were first roughing, then finishing the program. Taking into account the selected parts of the blank is 45 \# steel, its good machinability and surface without crust, so the use of tip arc is $R=0.4$ when the turning tool cutting processing, which can improve the processing of parts the surface roughness and tool wear can be reduced. When the internal bore and the inner contour, taking into account the accuracy of the machining of precision and positioning, can be used within 93 degrees hole tools, carry out roughing and finishing process, will be able to meet the requirements of precision parts. [3]

\section{Select the processing line}

In determining the processing line, it should follow the principle of "first base, the first hole behind after the first crude refined."

According to the characteristics of the blank, in the process, select the bottom face as a positioning reference plane, the first in chronological order, first drilled and then the inner surface of the rough parts of d20 hole, and then were roughing, finishing inside part contour, taking into parts Isolation is required to make a soft jaws to ensure positioning accuracy of the work piece. [4]

\section{Select the cutting parameters}

Because parts of the blank choice is 45 \# steel, so the processing performance of its cutting, the use of machining used machines are $\mathrm{CNC}$ lathes, taking into account the actual use of CNC lathes of performance and processing characteristics of its knife back to eat the amount of maximum the value of $1 \mathrm{~mm}$, and because the surface roughness of the machined parts is higher, so the need for rough machining, finishing, so when roughing, cutting back the amount of food choice MID is $0.2 \mathrm{~mm}$, finishing Select finishing allowance of $0.1 \mathrm{~mm}$. Also, because the machine feed rate is $0.1 \mathrm{~mm} / \mathrm{r}$, so in order to improve the efficiency of processing, roughing, contour selected direction feed amount (ie FFP1) of $0.2 \mathrm{~mm} / \mathrm{r} .^{[5]}$

Since the processing of parts and materials for the 45 \# steel, its good cutting performance, and the selected feed rate and the back of cut are relatively small, so by the look-up table reference, the cutting speed can get bigger, so choose cutting speed of $160 \mathrm{~m} / \mathrm{min}$. So when machining end mill for turning parts, its spindle speed:

$$
n=\frac{1000 \times v}{\pi \times d}=650 \mathrm{r} / \mathrm{min}
$$

After calculation available, choose its roughing spindle speed 650r / min, finishing spindle speed 1000r / min. Selection cutting three elements are shown in Table 2[6]

TABLe II Cutting Three Elements

\begin{tabular}{|c|c|c|c|c|}
\hline \multirow[b]{3}{*}{ Roughing } & \multirow{3}{*}{$\begin{array}{c}\text { Spindle speed } \\
(\mathrm{r} / \mathrm{min}) \\
650\end{array}$} & \multicolumn{2}{|c|}{ Feed rate $(\mathrm{mm} / \mathrm{r})$} & \multirow{3}{*}{$\begin{array}{c}\text { The back of } \\
\text { cut }(\mathrm{mm}) \\
1.0\end{array}$} \\
\hline & & FAL & FALD & \\
\hline & & 0.2 & 0.2 & \\
\hline Finishing & 1000 & 0.1 & 0.1 & 0.1 \\
\hline
\end{tabular}

Select the tool

Turning on all surfaces of parts, using drill through the center $\mathrm{O}$ processing, in order to improve the surface finish of precision parts, to avoid marks at the junction of the tool, so that the diameter should try a large selection of tools more, so turning parts of the surface, through the center of the selected $U$ drill diameter $20 \mathrm{~mm}$. The cemented carbide tool material, good stiffness, rigidity to meet processing requirements. [7] 


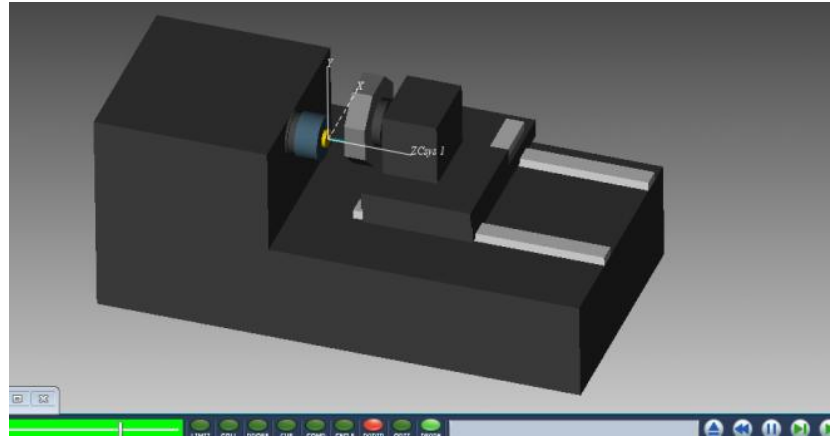

Figure 2. Work Piece Tool Installation Effect Map

\section{A. The work Piece Coordinate System}

Select the center of the upper surface of the work piece as the origin of the work piece coordinate system. As shown in diagram 3 :

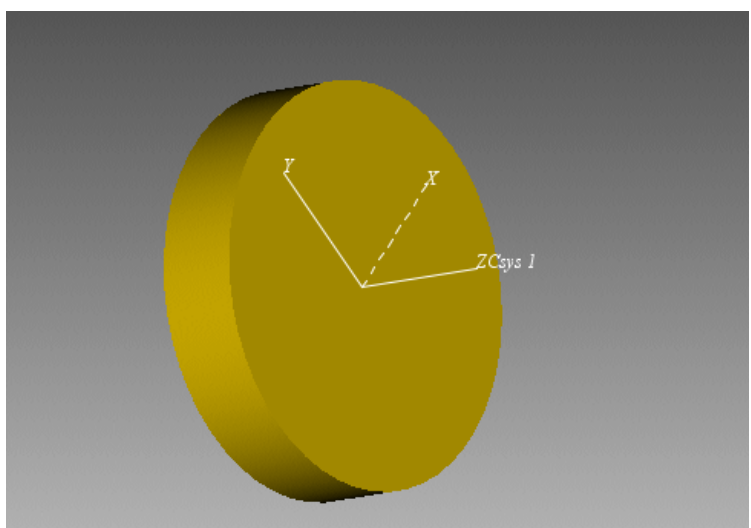

Figure 3. Setting the Work Piece Coordinate System

$\mathrm{NC}$ machining processes and tool card

According to the structural characteristics of the parts, press parts chucking positioning division process, due to the different structure and shape of each part, the technical requirements of each of the machined surface are different, their positioning will vary. Bottom and side of the work piece to be positioned, by stepping up fixture. In a process step, after all the processing surface by roughing finishing first step to divide. [8]

TABle III Parts CNC MachinIng Process CARD

\begin{tabular}{|c|c|c|c|c|c|c|c|}
\hline $\begin{array}{l}\text { Worker } \\
\text { number }\end{array}$ & Step Content & Tool number & $\begin{array}{c}\text { Tool } \\
\text { Specifications }\end{array}$ & $\begin{array}{l}\text { Spindle speed } \\
\text { (r/min) }\end{array}$ & $\begin{array}{l}\text { Feed rate } \\
(\mathrm{mm} / \mathrm{r})\end{array}$ & $\begin{array}{l}\text { The back of cut } \\
\text { (mm) }\end{array}$ & Remark \\
\hline 1 & Drill hole D20 & $\mathrm{T} 1$ & D20U 钻 & 650 & 0.2 & 20 & Automatic \\
\hline 2 & Roughing D82 through hole & $\mathrm{T} 1$ & D20U 钻 & 650 & 0.2 & 1 & Automatic \\
\hline 3 & Rough outline of the vehicle & $\mathrm{T} 1$ & $\mathrm{D} 20 \mathrm{U}$ 钻 & 650 & 0.2 & 1 & Automatic \\
\hline 4 & Refined interior contours & $\mathrm{T} 1$ & $\mathrm{D} 20 \mathrm{U}$ 钻 & 1000 & 0.1 & 0.1 & Automatic \\
\hline
\end{tabular}
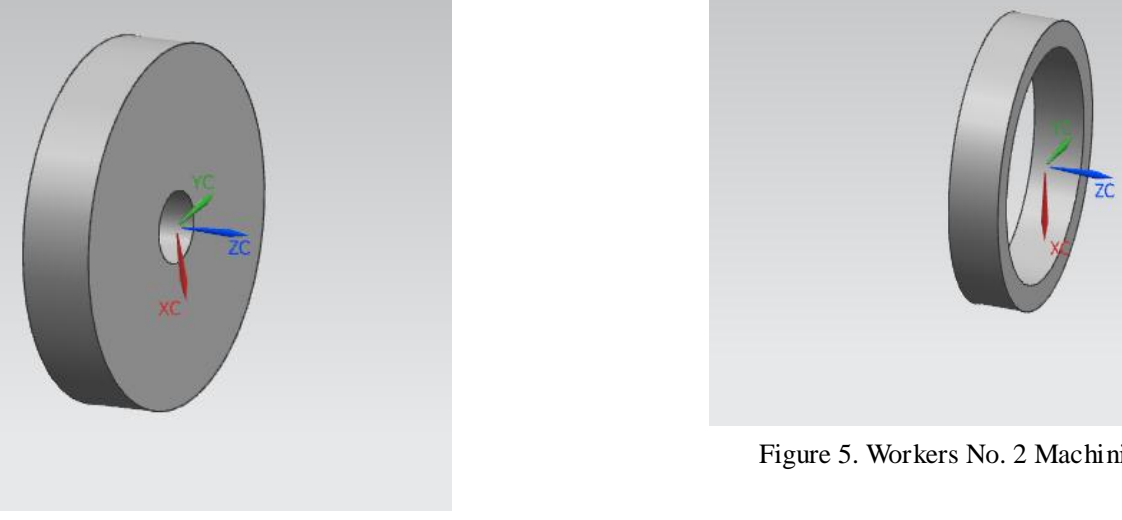

Figure 5. Workers No. 2 Machining Renderings

Figure 4. Workers No. 1 Machining Renderings 


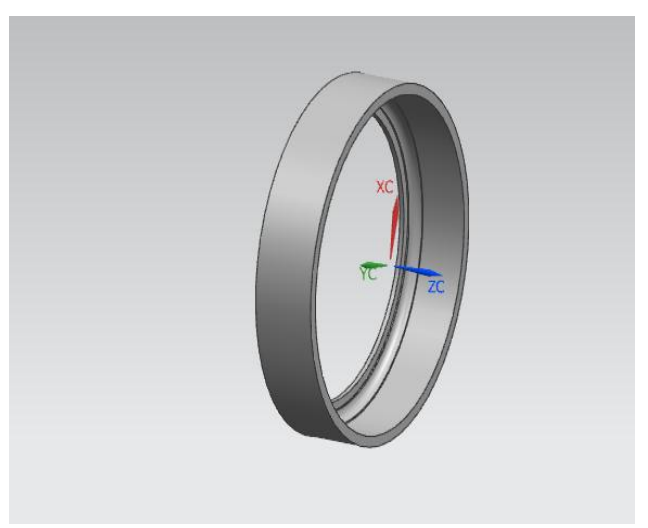

Figure 6. Workers No. 3 Machining Renderings

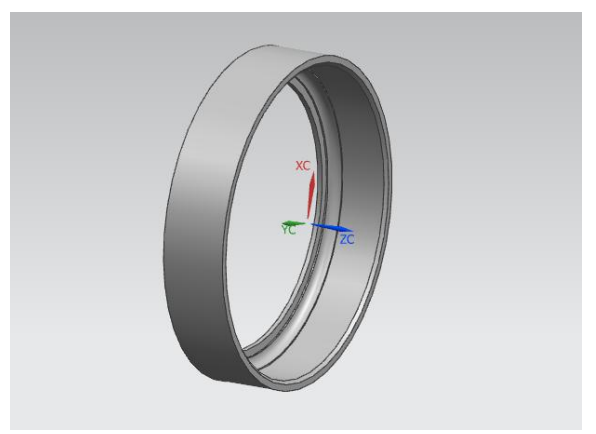

Figure 7. Workers No. 3 Machining Renderings

B. Processing procedures are as follows[9]

O1212

T0101;

M3S650;

G0X20Z2;

$\# 1=0$;

$\# 2=20$;

WHILE[\#1LE\#2]DO1;

G0Z3;

G0Z[-\#1+1];

G1Z-[\#1]F0.2;

$\# 1=\# 1+1$;

END1;

G0Z0;

G1X102F0.2;

G0Z1;

$\mathrm{X} 11$;

$\# 3=20$;

$\# 4=80$;

WHILE[\#3LE\#4]DO2;

G0X[\#3];

G1Z-21F0.2;

G0X[\#3-0.2];

$\mathrm{ZO}$;
$\# 3=\# 3+2$;

END2;

G0X80Z2;

G71U1R0.2;

G71P1Q2U0.2W0.2F0.2;

N1G0X95;

G1Z0;

G1X94Z-1 ;

Z-15;

X93;

G3X87Z-18R3;

G1Z-18.5;

$\mathrm{X} 82$;

$\mathrm{Z}-21$;

$\mathrm{N} 2 \mathrm{X} 80$

M3S1500;

G70P1Q2F0.1;

G0Z100;

M30;

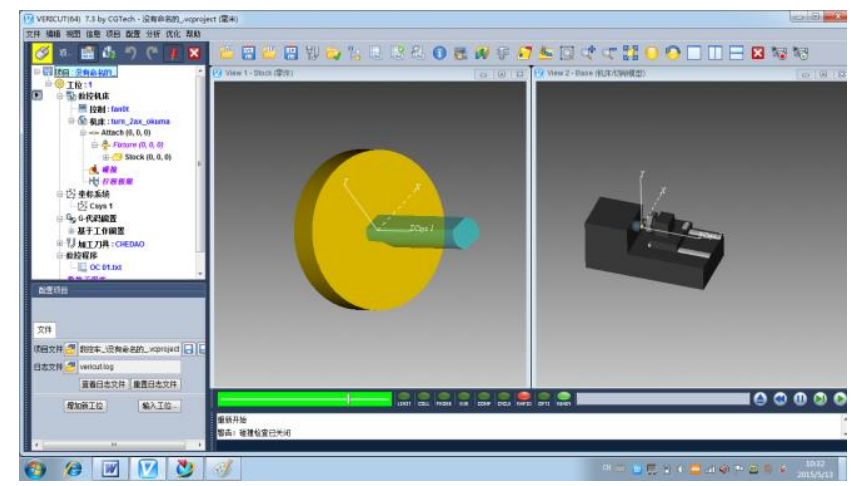

Figure 8. VERICUT Simulation Renderings

\section{CONCLUSION}

By programming the study of thin-walled parts $\mathrm{CNC}$ lathe macro program, find the preparation of complex parts on law macro CNC machine tools. CNC lathe designed for thin-walled parts programmed to $\mathrm{NC}$ programming personnel, in actual machining macro programs to be compiled according to the specific circumstances of the parts, in the processing of the application macro, so that simplify programming, programming of versatility. In NC programming, play a very important role. [10]

NC programmers will help improve the process, so as to solve the problems encountered in the business of CNC machining; Help enterprises processing components save time and improve efficiency; Conducive to the promotion of a macro program, so that more practitioners recognize the importance of the NC macro program, which independent macro program to stimulate interest in learning. 


\section{REFERENCES}

[1]Xiaojun Min UG NC Automatic Programming classic example of Machinery lndustry Press2011

[2]Chen Haizhou CNC milling macro program and application examples Machinery lndustry Press, 2006.

[3] Shen Chun-gen CNC milling macro programming examples succinctly Machinery lndustry Press 2014

[4]FANUC 0i Mate Mc Operating lnstructions Beijing Fanuc Company 2006

[5]Wang Rongxing machining center Curriculums Machinery lndustry
Press, 2006

[6]Gan Chengjun. On the Z-axis positioning of the workpiece clamping method CNC lathe [J]. Machine Tool \& Hydraulics.2011.14

[7] Yang Yanhua.Description of CNC turning tool selection [J]. China New Technology and New Products.2011.13

[8]Cheng Feifan. Discussion mold parts CNC Machining Process [J]. Electromechanical Information.2011.24

[9]Feng Zhigang. FANUC CNC macro programming system examples Machinery Industry Press 2013.

[10] Du Jun FANUC macro programming techniques and examples succinctly Chemical Industry Press 2011. 